\title{
Redefining the Water-Food-Energy Nexus for Biofuels: How to Mitigate the COVID-19 Pandemic Effects in Canada
}

\author{
Fatih Sekercioglu and Jiuqi Ma
}

\section{ABSTRACT}

Ensuring access to affordable, reliable, sustainable and modern energy for all, is a recognized Sustainable Development Goal. Yet the COVID-19 pandemic poses great challenges to the provision of bioenergy in Canada. Our study aims to examine these challenges by applying the Water-FoodEnergy (WEF) Nexus Approach and suggest an alternative policy framework in the post-COVID-19 recovery process. The paper analyzes the socio-economic and environmental impacts of COVID-19 and draws upon the bioenergy management strategies and policies in Canada, as well as other countries. The revised policy framework is built by considering the interactions across the WEF Nexus and adopting the experience from international examples, which could effectively minimize the shortcomings of the existing Canadian policy framework. Decision-makers may use our framework to overcome challenges created by the COVID-19 pandemic and ensure smooth bioenergy development and provision amid this global crisis.

Keywords: Bioenergy, COVID-19, Policy, WEF Nexus Approach.

Published Online: September 16, 2020

ISSN: $2684-5199$

DOI :10.24018/ejbio.2020.1.5.62

\section{Fatih Sekercioglu*}

School of Occupational and Public Health, Ryerson University, Toronto, ON, Canada.

(e-mail: fsekercioglu@ ryerson.ca)

\section{Jiuqi Ma}

School of Occupational and Public Health, Ryerson University, Toronto, ON, Canada.

(e-mail: jiuqi.ma@ryerson.ca)

*Corresponding Author

\section{INTRODUCTION}

Bioenergy is a renewable energy resource that can be derived from various types of biomass. In Canada, common sources of biomass are mainly agricultural and forestry residues [1]. Residues are treated and converted into general bioenergy. Bioenergy in Canada is usually employed in the form of biofuel, which acts as an additive in fossil fuel to satisfy transportation needs to help lower Greenhouse gas (GHG) emissions [2].

While shifting to renewable resources is emerging as a global trend to prevent climate change and fight against the depletion of fossil fuel reserves [3], in 2015, Canada embraced the Agenda for Sustainable Development directed by the United Nations. One of the goals (Goal 7) was set to ensure "access to affordable, reliable, sustainable and modern energy for all" by 2030. As calculated by Natural Resources Canada, in 2017, renewable sources already constituted $17.3 \%$ of Canada's total energy supply, whereas the average percentage of the world is only $13.6 \%$ [4].

However, as the COVID-19 pandemic struck Canada as well as other countries, the bioenergy sector, primarily biofuel production business, has been facing more challenges than any other sectors in market [5], due to impacts such as the rapidly declining price of conventional fuel, lowering demands of fuels and disrupted industrial supply chain during lockdown period [6]. The falling price of fossil fuels and market demands are likely to exacerbate bioenergy insecurity since biofuels are no longer considered cost-efficient or competitive to their producers; furthermore, some marginal producers may face consolidation, which could encourage monopoly and be detrimental to the current market. On the other hand, disrupted supply chain and work schedules could seriously impede the clean energy transition process in Canada. For instance, Environment and Climate Change Canada postponed the enactment of relevant regulations in Clean Fuel Standard [7], which is a crucial step in Canada's commitment to the Sustainable Development Goal (SDG) of Clean Energy.

The disturbance of biofuel provision has not yet surfaced as the most urgent problem amid the COVID-19 pandemic in developed countries such as Canada. Still, during this challenging time, the biofuel sector must be proactively protected from insecurity or even discontinuance, only through feasible protection strategies can the green energy be sustainably delivered to Canadians. Given this, our study, expanding on the potential causes of biofuel insecurity, outlines the current bioenergy management strategies in Canada and then proposes a unique framework based on the analysis of several international strategies for the decisionmakers to support a smooth delivery of bioenergy now and in the future. 


\section{CAuses of Biofuel Security}

The causes of biofuel insecurity will be analyzed in two parts: (1) explicit barrier that exists in the current bioenergy delivery process; (2) inexplicit barriers that hinder bioenergy delivery, which may be overlooked in the decision-making process.

\section{A. Explicit Barrier}

As identified by the World Bioenergy Association [5], the primary barrier that lies in the bioenergy supply chain is unstable feedstock procurement. Fig. 1 is a schematic drawing of the complete bioenergy supply chain, which is driven by the commitment of developing sustainable sources to replace fossil fuels.

After collection, some feedstocks are temporarily stored while others are transported to treatment facilities to be prepared for conversion. The pre-treatment step is required primarily for biomass, which will later be converted to liquid biofuels [8]. After the desired products (heat, electricity and biofuels) are produced through various conversion technologies, they will be adequately transported to consumption point and distributed accordingly.

Hence, there is no doubt that biomass collection is the most crucial steppingstone on the way to sustainable bioenergy provision, as it initiates the treatment process and serves as an indicator of the capacity of domestic bioenergy production.

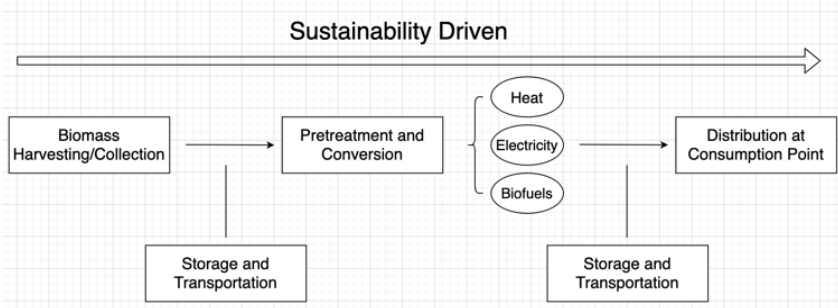

Fig. 1. Bioenergy Supply Chain (own drawing, adapted from Fig. 14 of [9]).

Yet fuel demand continues to drop since social distancing measures prohibit non-essential travels. Consequently, the need of the fuel additive - ethanol, has declined as well. The Renewable Fuels Association (RFA) of the United States (U.S.) warned that the value of ethanol sold is likely to decrease by $40 \%$ [10]. From this point of view, the U.S. researchers forecast a significant reduction in the average price of corn in the 2019-2020 marketing year as well [11], since a significant amount of corn is to be used for ethanol production. The situation is found the same in Ontario (Fig. 2). If the price of crops continues to decrease, the growers will be discouraged since there is no economic incentive driving them to grow corn for bioenergy use.

If social distancing measures and travel advisory are no longer in force in the near future, the demand of ethanol will rise quickly; yet as a result from discouragement in corn growing, it will not be possible for the supply to fully correspond to the demand in time, since the feedstock at that time is insufficient for vast harvesting. Thus, the rest of the steps in the biofuel supply chain will as well be delayed.

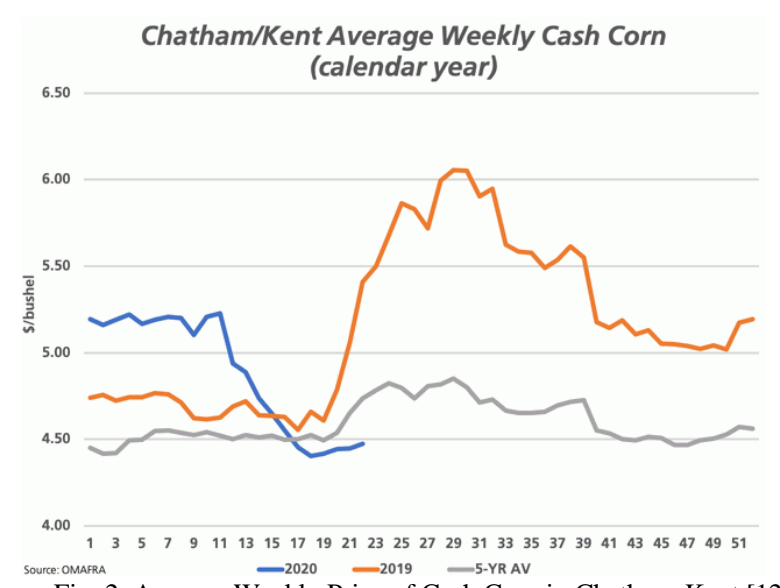

Fig. 2. Average Weekly Price of Cash Corn in Chatham-Kent [12]

To overcome this barrier, relevant policies should be developed to ensure stable feedstock is continuously provided, either through investing in growing other crops for biomass harvesting or through manually providing incentives to secure corn growing.

\section{B. Inexplicit Barriers}

As discussed above, bioenergy insecurity directly connects to the demand slump. However, one's imagination and perception towards sustainability and insecurity prevention strategies might be limited if only fixing sight on the energy sector or intuitively ignoring the natural interactions between energy and other vital resources in a broader scope.

To avoid ignorance and further develop a holistic understanding of sustainability, the United Nations advocates have been focusing on the numerous interlinkages between various SDGs. One of the central approaches the United Nations adopted was the Water-Energy-Food (WEF) Nexus, which encompasses the two other vital resources in addition to energy.

The WEF Nexus Approach (Fig. 3) was initially brought up at the Bonn Nexus Conference in 2011 [13]. It instantly grasped attention and has been well researched, followed by fruitful discoveries. The WEF Nexus as a whole could be pressurized by global trends, such as urbanization, population growth, and climate change. Also, significant alterations in the action field (society, economy, environment) could endanger resource security within the Nexus. Usually, the governance mechanism grows incrementally to accommodate predictable trends and helps restore harmony across the Nexus.

Meanwhile, the interlinkages within the Nexus summarize that 1 . water is essential to energy production; 2 . energy is necessary to water treatment and distribution; 3 . water is required for cultivation and irrigation, crops ensure proper drainage for excess water; and lastly, 4. food security provides continuous energy production, and energy continuously runs industries in food production and transportation [14]. Therefore, the WEF Nexus is viewed as a holistic vehicle to promote sustainable utilization of resources and preserve the ecosystem.

The significance of water, energy and food security in achieving sustainability is evidenced by the fact that they are all recognized as crucial SDGs in the U.N.'s agenda. Water security corresponds to SDG (6): provision of clean water and 
sanitation; as water becomes readily available and accessible, SDG (2): zero hunger could be achieved; thus, abundant agricultural leftovers could be used as feedstocks to boost bioenergy production.

Because of the sudden onset of the COVID-19 pandemic, the governance mechanism needs to be refreshed to ease the pressure. Thoroughly analyzing the underlying impacts of the pandemic on the Nexus and establishing appropriate governance strategies are critical for rebuilding resource security promptly.

The following subsections will illustrate the impacts of COVID-19 pandemic in the action fields and examine their potential in undermining biofuel security in Canada.

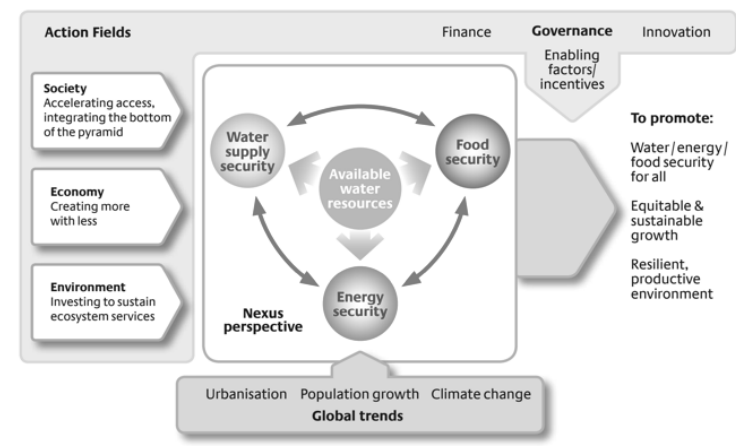

Fig. 3. The Water, Energy, and Food Security Nexus [13].

1. Socio-economic Impact of COVID-19 pandemic on WEF Nexus

One of the most worrisome socio-economic impacts of the COVID-19 pandemic is the spiking unemployment rate. As Statistics Canada's report highlighted, the unemployment rate reached $13.7 \%$ in May. It was the highest rate ever recorded since the database became available in 1976 [15]. The unemployment rate instantly triggered instability of household income and limited access to particular nourishment, which fundamentally increased the prevalence of food security in Canada. The most recent web panel survey conducted by Statistics Canada in May, the same month as the unemployment rate reached the apogee, has shown that although subsidies including Canada Emergency Response Benefit are in place, the level of food insecurity still increased significantly (14.6\%), when compared to the result of the last survey from 2017/2018 (10.5\%) [16].

On the supply side, shortage of work force and mandatory social distancing measure reduced the ability of the primary and secondary production line like farms and food processing plants, which further restricts timely resources delivery to retailers.

The concern of food insecurity is not growing only in developed countries like Canada. Developing countries in South America, Africa and Asia, which already have a long history of experiencing hunger before the global hit of the pandemic, are facing even severe circumstances. The United Nations Development Programme (UNDP) recognizes this as one of the key obstacles in their snapshot of COVID-19 pandemic impact assessment in developing countries, stating that millions are at risk of acute food security due to unemployment by the end of 2020 [17].

As biofuel addition and GHG emission reduction became the megatrend throughout the globe years ago, certain developed countries, including Canada, have encountered difficulties reaching the progressing ethanol additive standard while relying on domestic biofuel productions. Therefore, developing countries, including Brazil and Argentina, entered the biofuel market so that they could help close the gap in the demand of the first-generation biofuel in developed countries by exporting domestic crops while obtaining the profit to boost the income level of farmers in rural areas [18]. Up until today, Brazil and Argentina remain the largest exporting countries of biofuels.

Fig. 4 visualizes the proportion of biofuel imports and exports in Canada from 2006-2015 [19]. The volume of biofuel imports holds a much more significant share than total exports; there is a strong likelihood that the reliance on imports will remain as a constant phenomenon. This observation was augmented by the 2019 annual report prepared for Canada by the Foreign Agricultural Service of the United States Department of Agriculture (USDA). The report stated that the national demand for ethanol is 3.2 billion litres, yet, only less than 1.8 billion litres were produced locally, the outstanding amount (44\% of the market) was fulfilled purely through imports [20].

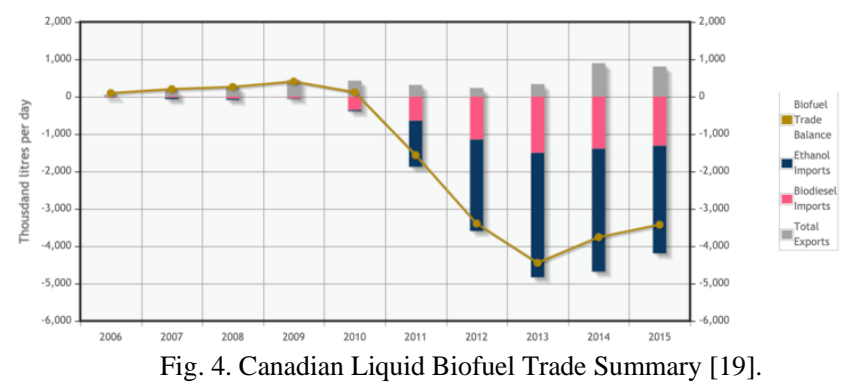

However, before the COVID-19 pandemic, there were already decisive views claiming that cultivating and exporting feedstocks for first-generation biofuel production would exacerbate food insecurity in developing countries, instead of easing it [21], [22].

In the current situation where food insecurity is already a significant problem in developing countries while they are still combating against the transmission of the virus, biofuel exporting is impossible to be, nor should it be the top priority. Without help, many developed countries will be put in risk of biofuel deficiency and delays in meeting clean energy goals.

As mentioned previously, the nature of WEF Nexus underpins the fact that food insecurity will impair the energy sector in general. Indeed, the expansion of food insecurity in developing countries nowadays is truly posing the possibility of bioenergy insecurity in developed countries as well. The dependency on first-generation biofuel imports is one significant barrier exposed due to the socio-economic impacts of the COVID-19 pandemic. Perhaps it is time for Canada to shift the reliance on the first-generation biofuel to more advanced, second-generation biofuels that could be sourced locally from animal and plant wastes, converted into bioenergy with higher efficiency and minimal impact on food security. Although second-generation biofuel requires much more financial input in terms of infrastructures and technology development, we must dedicate that effort to 
benefit future generations, instead of merely shifting the pressure to third-world countries to aggravate food insecurity and inequalities.

\section{Environmental Impact of COVID-19 Pandemic on} WEF Nexus

Although recent restrictions enacted by governments have limited anthropogenic activities which thus temporarily reduced the burden of air pollution, and carbon dioxide emission globally [23], the occurrence of inappropriate disposal of personal protective equipment (PPE) waste is rising and encroaching the residential sewage system. The public has recognized the importance of wearing face masks and gloves and used PPE more frequently ever since the health authorities designated these measures as the most effective strategies to protect from contracting the virus. However, since these preventive measures were newly formed under a pandemic context, the public is unfamiliar with the proper disposal methods. As a result, some people flush their used PPEs down the toilet instead of putting them in the garbage bin for waste collection. Various news sources have been reporting the sewage back-up issues in Canada caused by the flushing of single-use masks, gloves, sanitary wipes, and many other non-flushable items [24], [25], [26]. Although sewer clogging is not considered a recently developed symptom in populated urban areas, the ongoing PPE use unquestionably magnifies the existing problem.

The clogging issue is currently posing a risk to the municipal sewage system. If the paradox is to be left unsolved, it has the potential to cause multiple pipeline failures. Defective pipelines are considered causes of source water contamination in urban areas [27]. Hence if sewage contains microplastic particles seeps through the pipe before reaching treatment plant. At the same time, maintenance work could not be done on time due to a reduced workforce; it will ultimately lead to point source pollution of the source water.

As discussed in WEF Nexus interactions, water plays an essential role in bioenergy production. While a substantial amount of studies analyzed the impact of bioenergy production on water bodies, much fewer studies discussed the effect of water quality and quantity on bioenergy.

A noteworthy point in direct water-energy interlinkage is that the biomass to biofuel conversion process requires the involvement of large volume of high-purity water, which is usually taken from aquifers; if a processing facility produces 100 million gallons of ethanol annually, it will consume approximately 300 to 400 million gallons of water per year, an amount that is able to satisfy the water needs of 5000 people [28].

Therefore, it is reasonable to conclude that the yield and quality of biofuel are dependent on the quality and quantity of source water. Biofuel security may be pushed onto the edge if the freshwater reservoir is continuously polluted.

Furthermore, since water is considered the central element in the original WEF Nexus approach, to ensure the sustainability of energy or all types of sustainability in general in the current context, it all narrows down to a root issue of easing source water pollution by adequately disposing used masks and gloves. One of the barriers to solving this problem is the inefficient public communication regarding appropriate disposal manners. The federal and provincial governments in Canada are predominantly providing guidelines on how to don and doff PPEs securely, but the section for mask disposal is typically relatively short and vague. Information from official websites usually only briefly suggests discarding soiled face coverings into lined garbage bags. Yet, it does not warn otherwise that none of the PPE should be sent into the sewage system.

The public cannot generally self-determine the boundaries of appropriateness unless step-by-step instructions are given explicitly. Moreover, both the public and the authorities seem to overlook the significance of waste management at this particular time. This is temporarily justifiable because the foremost priority is to reduce or eliminate the transmission of the disease. However, the authorities need to find a critical balance in this trade-off process to reduce water pollution proactively, therefore to avoid turbulence in the energy sector - considering that not only bioenergy but also hydropower, Canada's primary renewable energy source is also depending on water availability.

Overall, the explicit and inexplicit barriers identified above are potentially jeopardizing the sustainable provision of bioenergy amid the COVID-19 pandemic. In other words, if examining from Fig. 4 (Pressurized Nexus) 's perspective, explicit and inexplicit barriers could all be considered as exposures that will presumably affect the outcome (sustainability). However, the governance strategies, as the intervening variable, is also a significant part in the established equation since it is capable of removing the barriers and restoring the harmony of the WEF Nexus. The next few sections will thus focus on biofuel management strategies and policies in various countries.

\section{MANAGEMENT OF BIOFUEL PROGRAMS}

Since biofuel production can be easily affected by social, political, economic, and environmental conditions, management strategies and relevant policies are subject to intrinsically vary from nation to nation, or even region to region. However, the central value remains constant: shifting the market demand from fossil fuel to biofuel. Each country is expected to enter the modern power market where the competitiveness of biofuel is further enhanced, to accelerate the deployment of bioenergy and to meet the SDG target. This is the exact motive that brings popularity into biofuel production in many participating countries, yet WHO suggested that renewable energy production still needs to hasten its pace to make substantial achievements by the 2030 deadline, without sacrificing the positive synergies between principals in the WEF Nexus.

The International Renewable Energy Agency (IRENA) proposed that to meet the set objectives of renewable energy adoption, a combination of basic policy measures must be put in place. These policies include: (1) direct policies, (2) enabling policies, and (3) integrating policies [29].

As defined by IRENA, direct policies are those governmental supports that directly prompt the increase in renewable energy share in power sector; enabling policies are sought to enhance the reliability and competitiveness of such 
production; finally, integrating policies help accommodate the emerging renewables into the frame of consumers' life by developing necessary projects and infrastructures.

Canada developed three specific operations, which respectively correspond to the three types of policies: (i) publishing and enforcing biofuel blending mandates, (ii) setting fiscal incentives such as tax reduction or interest-free loans, and (iii) project investment [30].

In the last section, we introduce three barriers that may affect the performance and delivery of biofuel in Canada during the COVID-19 pandemic. The subsections will firstly discuss government policies and management strategies in the Canadian biofuel sector in detail, then outline particular approaches adopted by other countries that are capable of dissolving the remaining barriers.

\section{A. Current Management Strategies and Policies in Canada}

The federal government in Canada is the primary player in providing blending mandates and fiscal incentives regarding biofuel production and use.

The Federal Renewable Fuels Regulations enacted in 2010 required that producers and importers must ensure at least $5 \%$ of the gasoline volume and $2 \%$ of the diesel volume that they produce or import must be from renewable sources. Canada is committed to reducing its total GHG emissions by $17 \%$ from 2005 level by the end of 2020 [31]. The novel Clean Fuel Standard (CFS), whose enactment is delayed due to the pandemic, is subject to replace the Renewable Fuels Regulations in 2022. The CFS sets an ambitious framework that aims to reduce national carbon emission by $30 \%$ (from the 2005 level) by 2030 [32].

Furthermore, the CFS provides financial incentives by allowing biofuel producers and importers to generate credits according to the amount of biofuel they contribute to the market. Credits will be calculated and issued by Environment and Climate Change Canada, which can be used for further trading and banking purposes.

As for the aspect of project investment, the federal government has generously provided funding to expand the understanding of practical biofuel applications. Table 1 is a summary of these federally funded programs.

While some of the provincial governments are also allowed to set their biofuel blend percentage, the requirement in federal regulations always serves as the baseline. Now Saskatchewan and Manitoba are the two provinces that have higher rates of biofuel blended in gasoline than required by the federal statute, whereas British Columbia and Ontario hold higher percentages in biodiesel blending [33].

In terms of project funding programs, the availability varies drastically in-between provinces. Some highlighted new provincial programs including Alberta's Bioenergy Producer Program, which ran from October 2017 to March 2020 and allocated 63 million dollars to biofuel production facilities to stir up provincial operations [34]. Ontario's Low Carbon Innovation Fund which granted 25.8 million dollars to help researchers, entrepreneurs, and companies with clean and innovative technology applications [35]. These programs are branching from the core federal programs and their ultimate objective remains unchanged - providing financial assistance to maximize the potential of bioenergy development.

TABLE I: SUMMARY OF FEDERAL BIOFUEL PROGRAMS (SOURCED FROM NATURAL RESOURCES CANADA, 2020)

\begin{tabular}{|c|c|c|c|}
\hline Name of Program & Objectives & $\begin{array}{c}\text { Funding } \\
\text { Details }\end{array}$ & Time Span \\
\hline $\begin{array}{c}\text { The National } \\
\text { Renewable Diesel } \\
\text { Demonstration } \\
\text { Initiative (NRDDI) }\end{array}$ & $\begin{array}{c}\text { To } \\
\text { demonstrate } \\
\text { how the } \\
\text { application of } \\
\text { biodiesel can } \\
\text { be influenced } \\
\text { by Canadian } \\
\text { conditions }\end{array}$ & $\begin{array}{l}\text { This program } \\
\text { provided up } \\
\text { to } 50 \% \text { of the } \\
\text { approved } \\
\text { project's total } \\
\text { expense } \\
\text { (maximum } \\
\text { one (1) } \\
\text { million } \\
\text { dollars per } \\
\text { fiscal year) }\end{array}$ & $\begin{array}{c}2008-2010 \\
\text { (completed) }\end{array}$ \\
\hline $\begin{array}{c}\text { ecoEnergy for } \\
\text { Biofuels }\end{array}$ & $\begin{array}{l}\text { To provide } \\
\text { financial } \\
\text { assistance to } \\
\text { producers to } \\
\text { reduce the } \\
\text { risk of } \\
\text { unstable } \\
\text { feedstock and } \\
\text { fuel price }\end{array}$ & $\begin{array}{l}\text { This program } \\
\text { dispensed up } \\
\text { to } 1.5 \text { billion } \\
\text { dollars over a } \\
\text { span of } 9 \\
\text { years }\end{array}$ & $\begin{array}{c}\text { 2008-2017 } \\
\text { (completed) }\end{array}$ \\
\hline $\begin{array}{c}\text { Next-Generation } \\
\text { Biofuel Fund }\end{array}$ & $\begin{array}{c}\text { To ease the } \\
\text { financial risk } \\
\text { in } \\
\text { establishing } \\
\text { next- } \\
\text { generation* } \\
\text { biofuel } \\
\text { facilities }\end{array}$ & $\begin{array}{l}\text { This program } \\
\text { provided up } \\
\text { to } 40 \% \text { of the } \\
\text { approved } \\
\text { project's total } \\
\text { expense } \\
\text { (maximum } \\
\text { two hundred } \\
\text { (200) million } \\
\text { dollars per } \\
\text { project) }\end{array}$ & $\begin{array}{c}2007-2027 \\
\text { (active) }\end{array}$ \\
\hline
\end{tabular}

However, we are able to conclude that the three significant COVID-related barriers indicated above could not be adequately mitigated using the current policy framework.

Because firstly, there is no ongoing policy guarding the crop values against shrinking, the availability of feedstock is severely challenged. Furthermore, policies are favouring biofuel producers and importers, but leaving the feedstock providers - farmers behind. Although the federal and provincial governments are issuing emergency funds and assistance to farmers through various manners, none of the support is exclusively easing feedstock crisis.

Secondly, the CFS, which is still yet to be delivered, is deemed to raise the bar of biofuel production and usage even higher. As a result, the dependency on supplier countries is subject to rising yet again to keep Canada on track to reach this goal.

As for the last issue with improper waste disposal, it exposes the lack of engagement of the public and communication from authorities. A detailed plan on advocating appropriate personal waste disposal should be constructed to solve this emerging problem.

\section{B. Management Strategy to Ensure Feedstock Stability in the United States}

Before the pandemic, the U.S. has already structured the corresponding program to provide farmers with incentives to 
grow feedstocks for biofuel use.

The Biomass Crop Assistance Program (BCAP) was initially introduced in the Food, Conservation, and Energy Act of 2008 (also known as the "2008 Farm Bill) to provide subsidies directly to farmers to encourage them to produce feedstocks and connect with local biofuel plants [36]. BCAP was retained even though the Act was updated twice in the following years and has effectively prevented farmers from being negatively impacted by the fluctuation of crop prices.

Moreover, to deal with the present downturn situation, the Renewable Fuel Feedstock Reimbursement Act of 2020 was introduced in the U.S. Senate on May 19, 2020 [37]. This Act is entitled to reimburse domestic biofuel producers for feedstock-related purchases made between January and March. Quoting the Senator who introduced this legislation, "The biofuel industry works directly with our farmers, and the current disruptions from the pandemic have created... steep declines in corn and soybean prices. We need to continue to support those farmers who feed and fuel our country and the world."

This strategy is deemed to send a clear signal to farmers that the producers have regained the capital to purchase the feedstock. This can help the former group of individuals rebuild the confidence in crop growing and stabilize the biofuel supply chain, and along with the ongoing assistance from BCAP, the explicit barrier we have discussed above could be appropriately resolved.

Canada could adopt this insight in assisting farmers during economic hardships and constantly keeping other interested individuals informed about policy change, as well as the alternative path they could take, such as forming long-time business relationships with local biomass treatment facilities, if there is any.

\section{Management Strategies and Policies in Japan to Reduce Reliance on Imported Fuels}

Given its title of a "net food-importing country", Japan has the foresight to fully recognize the lack of reliability of importing crop-based, conventional biofuels.

With that being indicated, the Ministry of Economy, Trade and Industry (METI) adopted the Next-generation Vehicle and Fuel Initiative in 2007 [38]. The guideline report sets a reliable benchmark to lower the production cost of secondgeneration, locally sourced biofuels by 2015-2020. The report presented an incremental model to overcome technological and financial barriers in the path of pursuing the development of domestic biofuels.

Later in April 2014, the Cabinet adopted the Basic Energy Plan as a response to appease the chaos in the energy sector resulting from the Great East Japan Earthquake in 2011 [39]. The plan recognized once again the fundamental vulnerability induced by high dependency on import energy supplies. It also confirmed that interactions across society, economy, and environment sectors would have dramatic impacts on energy sustainability. More importantly, the plan outlined the goal of building a "multilayered and diversified flexible energy supply-demand structure" [39]. The purpose of this structure is to gradually take advantage of local waste and residues to minimize the external supply shock. Instead of reserving carbon-intensity and emission reduction as the central value as the western countries did, the plan underscored the importance of self-sufficiency and supply system reconfiguration. The government has given a tremendous commitment to domestic facilities and advanced bioenergy conversion technologies development through generous funding allocation. The renewable energy system reforming budgets represent about $78 \%$ of METI's total budget in the 2017 fiscal year [40].

So far in Canada, although there is an existing federal program providing funding for next-generation biofuel projects, the actual amount of money allocated to relevant facilities and projects (30 million dollars) is way lower than the total approved amount (250 million dollars) [41]. It will be beneficial to absorb the experience from Japan in terms of prioritizing the comprehension expansion and production of these advanced, locally sourced biofuels, to circumvent instances of bioenergy insecurity in the future, if food insecurity jeopardizes feedstocks importing once again.

D. Management Proposal in the United Kingdom to Control Water Pollution

Since plastic waste accumulation and water pollution became social hotspots rather recently, there is no concrete policy establishment to alter the circumstance immediately, but a relevant proposal has come out to provide solutions.

Earlier, the Plastic Waste Innovation Hub at University College London warned in their policy brief that wearing single-use masks has negative implications on the U.K.'s waste treatment stream [42]. It proposed that if used correctly, reusable masks could perform the same as single-use, plasticbased surgical masks. Still, without the simultaneous concern of impairing environmental protection when used daily, because through effective washing and disinfecting techniques, reusable masks could be kept for an extended period before disposal.

It suggested the government hold online public campaigns to support the use of reusable PPE over the single-use ones. Video tutorials and virtual communications could be put in place to unravel the myths and misunderstandings; that way, the public may feel more engaged in the process of mitigating plastic pollution while guarding themselves against the virus.

Similarly, both the federal and provincial governments of Canada could also encourage selling, purchasing and using reusable PPE. Meanwhile, resources regarding PPE use and disposal have to be consistently provided and promulgated; additional news-related references should also be included to ensure users to obtain thorough understanding of the reason behind the shift from single-used products.

As mandatory mask-wearing policy is being enacted throughout the world, promotion of reusable masks could be seen as an alternative measure to prevent improper waste disposal from harming the sewage system, thus eliminating source water pollution.

Moreover, reuse, reduce and recycle is the optimal approach within the waste management hierarchy, whereas waste clean-up and disposal are less preferred. This perspective also makes transition to reusable masks a more decent option when compared to vast disposal of fragile plastic PPE. 


\section{OVERVIEW OF THE INTERNATIONAL ENERGY AGENCY SUMMIT}

To further realize the impact of the COVID-19 pandemic on the renewable energy sector, and to facilitate communications across the globe, a virtual roundtable discussion was held by the International Energy Agency (IEA) on July 9, 2020. This event formally called the "IEA Clean Energy Transitions Summit," brought together the ministers from largest energy-consuming countries including Canada, as well as numerous non-governmental stakeholders such as CEOs and Presidents from major energy foundations and networks, to structure a preliminary plan to retain energy sustainability amid the crisis [43].

The discussion primarily focused on the report Clean Energy Innovation that was generated by IEA in July. The participants reiterated the five fundamental innovation principles that the decision-makers should be concerned with [44]:

- $\quad$ Prioritize, track, and adjust

- Raise research and development (R\&D) and marketled private innovation

- Address all links in the value chain

- Build enabling infrastructure

- Work globally for regional success

Most of the above opinions are overlapping with the strategies proposed in our revised framework. Specifically, if adding "prioritize, track, and adjust," "raise R\&D and private innovation," and "build enabling infrastructure" together, they could contribute the same as previously mentioned opportunity in prioritizing advanced local biofuel production and allocating large fund to build necessary facilities; and "address all links in the value chain" refers to being aware of possible interactions between all associating factors, which intrinsically urges the appreciation towards the current WEF Nexus and possibly beyond.

Overall, the takeaway points that could aid in our framework formation is to increase idea exchanges and the establishment of international partnerships to contribute to regional success.

\section{REVISED WEF NEXUS APPROACH AND POLICY FRAMEWORK}

Based on the issues found related to interrupted harmony across the WEF Nexus and the necessity to pave the road for sustainable bioenergy provision under the pressure of COVID-19 pandemic, the original WEF Nexus Approach was reconstructed (Fig. 5) to present the concept of this study more accurately. This novel representation accommodates the COVID-19 pandemic as the newly formed variable in the flow towards sustainability.

In this model, the COVID-19 pandemic is considered as a "nexus shock" since it conforms to the definition, "The shocks are... often unlikely, rare events, but they have large, at times, catastrophic consequences [45]." As mentioned previously, so far in Canada, this shock has affected social, economic, and environmental fields; the influence embodies the escalating issues and hot spots that eventually lead to insecurity of vital resources, which subsequently necessitate and urge the development of corresponding governance strategies. It is not possible to reverse the negative impacts that have already been done, although through the implementation of remedial strategies, or in other words, through manipulation of the intervening variable, harm to sustainability can be reduced to the minimum level.

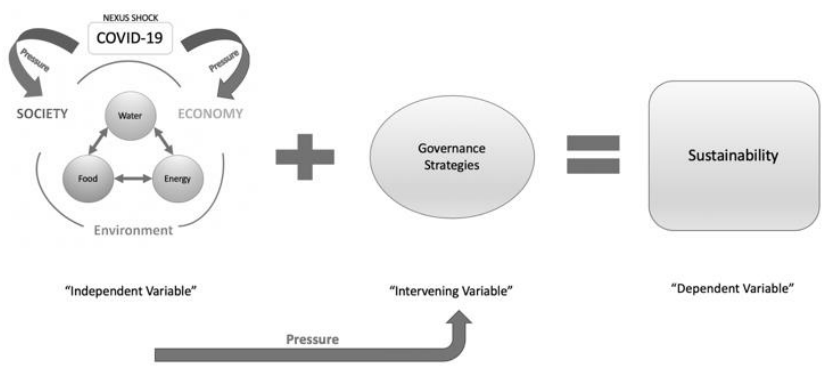

Fig. 5. Revised Nexus towards sustainability based on the COVID-19 pandemic effects.

Hence, we present this revised policy framework that adopts the essence of those international strategies and suggestions introduced in the previous section. As outlined in Table 2, our framework is composed of four general aspects; each aspect includes specific recommendations, which could be seen as pathways leading to improved bioenergy provision and fulfilment of SDG commitments in Canada.

TABLE II: REVISED POLICY FRAMEWORK TOWARDS SUSTAINABLE BIOENERGY PROVISION

\begin{tabular}{|c|c|}
\hline Aspects & Specific Recommendations \\
\hline $\begin{array}{l}\text { Ensure feedstock availability } \\
\text { and stability }\end{array}$ & $\begin{array}{l}\text { Setting up financial assistance } \\
\text { program to protect farmers from } \\
\text { unforeseen commodity price } \\
\text { shrinking; } \\
\text { Keeping farmers well-informed } \\
\text { about ongoing programs; } \\
\text { Encouraging farmers to form } \\
\text { business relationship with local } \\
\text { bioenergy facilities. }\end{array}$ \\
\hline $\begin{array}{l}\text { Maximize local biofuel } \\
\text { production capacities }\end{array}$ & $\begin{array}{l}\text { Shifting the R\&D focus to next- } \\
\text { generation biofuels; } \\
\text { Securing and dispensing funds to } \\
\text { advanced projects on time; } \\
\text { Evaluating the improving } \\
\text { development plan of existing } \\
\text { facilities, instead of building more } \\
\text { new ones. }\end{array}$ \\
\hline Reduce Source Water Pollution & $\begin{array}{l}\text { Promoting reusable PPE while } \\
\text { discouraging the use of single-use } \\
\text { products; } \\
\text { Enhancing public engagement in } \\
\text { mask using and disposal. }\end{array}$ \\
\hline $\begin{array}{l}\text { Increase international } \\
\text { collaboration }\end{array}$ & $\begin{array}{l}\text { Exchanging ideas of post-COVID } \\
\text { policy development; } \\
\text { Forming partnerships to seize future } \\
\text { opportunities. }\end{array}$ \\
\hline
\end{tabular}

\section{A. Ensure feedstock availability and stability}

As discussed above, we are in urgent need of constructing a financial assistance program to protect feedstock farmers from price shrinking exclusively. Once the program is implemented, it should be promoted broadly. Social media, 
newspapers could all be utilized to reach the target audience of this supportive measure. If more farmers decide to join in, the government should then provide approaches for them to form new business relationships with the local biofuel production facility. This strategy will hopefully create a positive feedback loop that secures the foremost step feedstock collection - in the biofuel supply chain.

\section{B. Maximize local biofuel production capacities}

Ultimately, we would like to decrease the dependency on imported, first-generation biofuels, which will post harm to food security and biodiversity but boost local biofuel productions. Since second-generation biofuels could be sourced locally from animal and residential wastes, shifting the R\&D focus to innovative extraction and conversion technologies is an essential step in achieving the goal.

To obtain promising outcomes from $\mathrm{R} \& \mathrm{D}$ processes, sufficient funding should be gradually dispensed by the government as these research projects progress. Furthermore, governmental funding should be spent wisely, especially at the present time in which our economy is facing stringent conditions. Evaluating and transforming the existing facilities into more advanced levels are considered optimal measures in producing next-generation biofuels.

Although investing time and money to promote the development of next-generation biofuels seems to hamper the available trade of conventional biofuel, it could eventually cut out the overwhelming reliance on supply from other countries and maximize the efficiency of biomass conversion. Now Canada is provided with an excellent opportunity to step out of its comfort zone. Canada should show a firm commitment to stressing the development of next-generation biofuels by encouraging and supporting relevant researches in terms of financial needs, and it should be made sure that each existing facility is running efficiently in terms of production capability before new facilities are built and put into use.

\section{Reduce Source Water Pollution}

Since medical waste is projected to continue to increase significantly, microplastic pollution will always present as a problem in water protection. The government should promote the use of reusable masks and gloves as a means to ease pollution, but only under the condition if Canadian-made reusable masks are proved to have the same strength in preventing virus infiltration. Further studies thus may be needed within this scope.

Once approved, the government should enhance public engagement and awareness in using, disinfecting, and disposing of these masks by providing information to assist in understanding the significance of "reuse, reduce \& recycle". All activities should always remain as "two-ways" interactions; the government should be open to alternative ideas and be ready to solve confusion and conflicts. With that being said, it is not reasonable to ban single-use PPE entirely. Instead, the government could advise through the display board online or along major roads that single-use products are not suitable to be flushed down the toilet. Ultimately, every party involved in the communication process should show a commitment to protecting water resources.

\section{Increase International Collaboration}

Planning for the COVID-19 pandemic recovery is a top priority for almost every country in the world. As the stakeholders suggested, it is salutary that countries "cooperate to share best practices, experiences and resources to tackle urgent and global technology challenges, including via existing multilateral platforms (IEA, 2020)." Virtual global communities could be built online, where various stakeholders are allowed to deliver their new thoughts on improving the recovery plan. Through idea exchanges and partnership formations, we can discover underlying issues and blind spots that have never been examined before. Broad thinking is always appreciated, especially when we are still struggling in the middle of this global hardship.

\section{DISCUSSION}

Water, energy, and food securities are considered central elements for sustainable development and should be protected from economic, social, and environmental challenges through adequate political practices.

The current policy framework is found not capable of exclusively and effectively resolving the contemporary issues brought by the COVID-19 pandemic. Thus, it may postpone Canada's commitment to alternative energy provision. Since biofuel management strategies and policies vary from country to country, we identified several international proposals and views which target similar concerns.

Our revised framework aims to offset bioenergy insecurity during the COVID-19 era by working collaboratively to set overarching goals to protect local sources.

In this study, we examined one explicit barrier that is directly associated with the demand drop. Then, through a comparison between the current situation and the ideal interactions across the WEF Nexus, we found two underlying barriers that are closely tied with food and water availability. These barriers are seemingly distant from the primary topic of energy provision. Yet, they could be well explained using the WEF rationale: that of the remaining two sectors predestines the performance of one sector. The revised framework is constructed to reduce the vulnerabilities in local biofuel production by setting strategies that could be presumably partaken by all levels of governments within Canada, to produce more balanced and outcomes equally throughout sectors.

Our model has one limitation due to the persistence of this pandemic: the federal and provincial governments may not be financially ready to set up assistance and advanced research programs. The Conference Board of Canada forecasts that the economy will contract $8.2 \%$ by the end of 2020 [46]. If the second wave of the pandemic arrives soon, it is reasonable for governments to enact austerity measures and cut peripheral expenses, to reduce budget deficits. In this scenario, where the revised framework could only be partially adopted, the problem of bioenergy insecurity may not be fully addressed and resolved.

Before adoption, further evaluations and self-assessments could be done by governmental bodies to rate the feasibility and characterize the potential drawbacks of this framework. 
Through weighing the gains against losses, the governments could develop more specific and versatile plans based upon the skeleton of our model, with the purpose of adjusting under distinctive fiscal conditions. Future studies could be conducted to figure out the potential drawbacks of these corrective measures and their compatibility in Canadian systems, to ensure they could be efficiently executed with maximum coherence.

\section{CONCLUSION}

Biofuel is a significant renewable energy source that is continuously expanding its share in the energy market. Bioenergy provision and development was recognized as one of the SDGs to be achieved by the year 2030 .

However, as a result of the COVID-19 pandemic, several issues have surfaced to hinder the provision of biofuels in Canada. Three barriers were detected following demand slump and supply chain disruption: (1) feedstock instability, (2) increasing dependence on import biofuels, and (3) water pollution due to inappropriate medical waste disposal. We adopted the WEF Nexus to deduct the occurrence of two inexplicit barriers that arise due to negative interactions between WEF sectors, which originated from the socioeconomic and environmental impacts of COVID-19. Using the insights from the equation established in the WEF Nexus Approach, we were able to conclude that effective governance strategies, as the only intervening variable, could offset the negative impacts brought by COVID-19 and restore the harmonious relationships among water, food, and energy sectors.

However, following the examination of Canada's regulatory regime from both federal and provincial levels, it is determined that the current policy framework has several weaknesses in resolving these barriers. Consequently, these weaknesses must be addressed for sustainable biofuel production. The revised policy framework, containing four aspects, is proposed to reach this goal.

Sustainability of renewable energy provision now lies in a more unstable position than ever before. Although with this being said, it does not entirely restrict us from acting swiftly to overcome the barriers. Post-COVID era could be an opportunistic period to make corrections and add effective measures into the present regime. With ongoing investments and improved comprehension in fostering positive interactions across the WEF Nexus, sustainable provision of bioenergy could be secured even more solidly than before.

\section{REFERENCES}

[1] A. A. Khan. "Potential Use of Biomass for Bio-Energy in Ontario," in Guelph Engineering Journal, (2), 39 - 44. ISSN: 1916-1107. (C2009.

[2] Natural Resources Canada (2020). Biodiesel. Retrieved July 12, 2020 from https://www.nrcan.gc.ca/energy-efficiency/energy-efficiencytransportation/alternative-fuels/biofuels/biodiesel/3509\#a6.

[3] S. Hadian and K. Madani. "A system of systems approach to energy sustainability assessment: Are all renewables really green?", Ecological Indicators, vol. 52, pp. 194-206. 2015.

[4] Natural Resources Canada. Renewable Energy Facts. Retrieved July 1 , 2020 from https://www.nrcan.gc.ca/science-data/data-analysis/energydata-analysis/renewable-energy-facts/20069.
[5] World Bioenergy Association (WBA) (2020). COVID19 and Bioenergy: Impacts and future outlook. Retrieved July 2, 2020, from https://worldbioenergy.org/index.php?mact=News,cntnt01,detail,0\&c ntnt01 articleid $=544 \&$ cntnt 01 returnid $=68$

[6] D. Chiaramonti and K. Maniatis. "Security of supply, strategic storage and Covid19: Which lessons learnt for renewable and recycled carbon fuels, and their future role in decarbonizing transport?", Applied Energy, 271, 115216. 2020.

[7] Government of Canada (2020). Clean Fuel Standard. Retrieved July 5, 2020, from https://www.canada.ca/en/environment-climatechange/services/managing-pollution/energy-production/fuelregulations/clean-fuel-standard.html.

[8] V. B. Agbor, N. Cicek, R. Sparling, A. Berlin and D. B. Levin "Biomass pretreatment: Fundamentals toward application", Biotechnology Advances, 29(6), pp. 675-685, 2011.

[9] L. Puigjaner, M. Pérez-Fortes and J. Laínez-Aguirre. "Towards a Carbon-Neutral Energy Sector: Opportunities and Challenges of Coordinated Bioenergy Supply Chains-A PSE Approach". Energies,8(6), pp. 5613-5660, 2015.

[10] Renewable Fuels Association (RFA) (2020). The Economic Impact of COVID-19 on the Ethanol Industry. Retrieved July 7, 2020 from https://ethanolrfa.org/wp-content/uploads/2020/04/COVID19Ethanol-Industry-Economic-Impact-20200420.pdf.

[11] C. E. Hart, D. J. Hayes, K. L. Jacobs, L. L. Schulz, J. M. Crespi. (April 2020). "The Impact of COVID-19 on Iowa's Corn, Soybean, Ethanol, Pork, and Beef Sectors". IOWA University, Centre for Agricultural and Rural Development Policy Brief [Online]. Available: https://www.card.iastate.edu/products/policy-briefs/display/?n=1301.

[12] C. Jamieson. (2020, June 16). Ontario Cash Corn Price Below Average. Retrieved July 05, 2020, from https://www.dtnpf.com/agriculture/web/ag/blogs/canadamarkets/blog-post/2020/06/16/ontario-cash-corn-price-average.

[13] H. Hoff. "Understanding the Nexus. Background Paper for the Bonn2011 Conference: The Water, Energy and Food Security Nexus", Stockholm Environment Institute, Stockholm. 2011.

[14] S. Xu, W. He, J. Shen, D. M. Degefu, L. Yuan, and Y. Kong. Coupling and Coordination Degrees of the Core Water-Energy-Food Nexus in China. International Journal of Environmental Research and Public Health, 16(9), 1648. 2019.

[15] Statistics Canada (2020). Labour Force Survey, May 2020. Retrieved June 29. 2020 from https://www150.statcan.gc.ca/n1/dailyquotidien/200605/dq200605a-eng.htm.

[16] Statistics Canada (2020). Food insecurity during the COVID-19 pandemic, May 2020. Retrieved June 29, 2020 from https://www150.statcan.gc.ca/n1/pub/45-280001/2020001/article/00039-eng.htm.

[17] United Nations Development Programme (2020). Brief\#2: Putting the U.N. Framework for Socio-Economic Response to COVID-19 in Action: Insights. Retrieved July 6, 2020, from https://www.undp.org/content/undp/en/home/coronavirus/socioeconomic-impact-of-covid-19.html.

[18] D. Boddiger. Boosting biofuel crops could threaten food security. The Lancet, 370(9591), pp. 923-924. 2007.

[19] Canada Energy Regulator (2016). Market Snapshot: Regulations and market conditions driving Canada-U.S. biofuel trade. Retrieved July 6 , 2020, from https://www.cer-rec.gc.ca/nrg/ntgrtd/mrkt/snpsht/2016/1102rgltnmrktcndtn-eng.html?=undefined \& wbdisable=true.

[20] United States Department of Agriculture Foreign Agriculture Service (USDA FAS) (2019). Canada, Biofuels Annual 2019. Retrieved July 22, 2020, from https://apps.fas.usda.gov/newgainapi/api/report/downloadreportbyfile name?filename=Biofuels\%20Annual_Ottawa_Canada_8-9-2019.pdf.

[21] N. Kiggundu, S. Arhin, N. Banadda and I. Kabenge. "Impacts of Biofuel Policies on Welfare and Food Security: Assessing the Socioeconomic and Environmental Trade-offs in Sub-Saharan Africa". International Journal of Renewable Energy Research. 7, pp. 21622171. 2017

[22] F. Hartley, D. V. Seventer, P. C. Samboko and C. Arndt. "Economywide implications of biofuel production in Zambia." Development Southern Africa, 36(2), pp. 213-232. 2018

[23] C. L. Quéré, R. B. Jackson, M. W. Jones, A. J. Smith, S. Abernethy, R. M. Andrew, ... G. P. Peters. "Temporary reduction in daily global CO2 emissions during the COVID-19 forced confinement". Nature Climate Change, 10(7), pp. 647-653. 2020.

[24] Chattha, S. (2020). Potential Impacts of an Unplanned Service Disruption on Water Delivery. Retrieved July 08, 2020, from https://www.watercanada.net/feature/potential-impacts-of-anunplanned-service-disruption-on-water-delivery/. 
[25] Clarke, K. (2020, June 18). Used COVID-19 gloves, masks and wipe clogging up Metro Vancouver sewage systems. Retrieved July 23 , 2020, from https://www.richmond-news.com/news/used-covid-19gloves-masks-and-wipes-clogging-up-metro-vancouver-sewagesystems-1.24155085.

[26] Rasmussen, G. (2020). Those COVID-19 masks, gloves and wipes we're all using are polluting land and sea $\mid \mathrm{CBC}$ News. Retrieved July 23, 2020, from https://www.cbc.ca/news/technology/masks-globeswipes-creating-garbage-1.5600870.

[27] L. Wolf, I. Held, M. Eiswirth, H. Hötzl. Impact of Leaky Sewers on Groundwater Quality. Acta Hydrochimica Et Hydrobiologica, 32(4-5), pp. 361-373. 2004.

[28] IOM (Institute of Medicine). 2014. The nexus of biofuels, climate change, and human health: Workshop summary. Washington, DC: The National Academies Press.

[29] International Renewable Energy Agency (IRENA) (2018), Renewable Energy Policies in a Time of Transition. IRENA, OECD/IEA and REN21.

[30] Canada's Ecofiscal Commission (2016). Course Correction: It's Time to Rethink Canadian Biofuel Policies. Retrieved July 21, 2020, from https://ecofiscal.ca/reports/course-correction-time-rethink-canadianbiofuel-policies/.

[31] Government of Canada (2018). Federal Renewable Fuels Regulations Overview. Retrieved July 11, 2020, from https://www.canada.ca/en/environment-climatechange/services/managing-pollution/energy-production/fuelregulations/renewable/overview.html.

[32] Environment and Climate Change Canada (2018). Clean Fuel Standard Regulatory Design. Retrived July 12, 2020, from https://www.canada.ca/en/environment-climate-

change/services/managing-pollution/energy-production/fuelregulations/clean-fuel-standard/regulatory-design.html\#toc4.

[33] Wolinetz, M., Hein, M., \& Moawad, B. (2020). 2019 Biofuels in Canada. Retrieved July 12, 2020, from https://www.naviusresearch.com/publications/2019-biofuels-incanada/.

[34] Government of Alberta (2017). Bioenergy Producer Program Outline Retrieved July 13, 2020, from https://open.alberta.ca/dataset/bioenergy-producer-program-outline.

[35] Government of Ontario (2017). Archived - Low Carbon Innovation Fund, Retrieved July 13, 2020, from https://www.ontario.ca/page/lowcarbon-innovation-

fund\#: :text=The\%20Low\%20Carbon\%20Innovation\%20Fund,its $\% 2$ 0GHG\%20emissions \%20reductions $\% 20$ targets.\&text=technology $\% 2$ 0validation\%20(e.g.\%20proof\%2Dof,\%2Dconcept\%20and\%20protot ype\%20development).

[36] United States Senate Committee on Agriculture, Nutrition \& Forestry (2008). 2008 Farm Bill. Retrieved July 13, 2020, from https://www.agriculture.senate.gov/issues/2008-farm-bill.

[37] Kotrba, R. (2020). Biofuel feedstock reimbursement act introduced in U.S. Senate. Retrieved July 13, 2020, from http://www.ethanolproducer.com/articles/17194/biofuel-feedstockreimbursement-act-introduced-in-us-senate.

[38] N. Matsumoto, D. Sano, M. Elder. "Biofuel initiatives in Japan: Strategies, policies, and future potential". Applied Energy, 86. 2009.

[39] Ministry of Economy, Trade and Industry of Japan (METI) (2014) Cabinet Decision on the New Strategic Energy Plan. Retrieved July 14 2020, from https://www.meti.go.jp/english/press/2014/0411_02.html.

[40] J. B. Kucharski, H. Unesaki. “Japan's 2014 Strategic Energy Plan: A Planned Energy System Transition”. Journal of Energy, pp. 1-13. 2017.

[41] Government of Canada (2016). Sustainable Development Technology Canada (SDTC) for the NextGen Biofuels Fund ${ }^{\mathrm{TM}}$. Retrieved July 13 2020, from https://www.nrcan.gc.ca/plans-performancereports/rpp/2015-16/17071.

[42] A. L. Allison, E. Ambrose-Dempster, T. D. Aparsi, M. Bawn, M. C Arredondo, C. Chau. J. Ward. The environmental dangers of employing single-use face masks as part of a COVID-19 exit strategy. 2020.

[43] International Energy Agency (IEA) (2020). IEA Clean Energy Transitions Summit. Retrieved July 16, 2020, from https://www.iea.org/events/iea-clean-energy-transitions-summit.

[44] International Energy Agency (IEA) (2020). Clean Energy Innovation. Retrieved July 16, 2020, from https://www.iea.org/reports/cleanenergy-innovation.

[45] C. Howarth. Informing National and International Responses to Shocks to the Energy-Food-Water-Environment Nexus; Living With Environmental Change: Swindon, U.K., 2016.
[46] Conference Board of Canada (2020). Canadian Outlook Summary: Summer 2020. Retrieved July 30, 2020, from https://www.conferenceboard.ca/e-library/abstract.aspx?did=10737. 